\title{
Cerebral astroblastoma with oligodendroglial-like cells
}

\section{A case report}

\author{
Jian Gu, MS ${ }^{a, b}$, Yihua Wang, MS ${ }^{a, b}$, Juanhan Yu, MD, PhD ${ }^{a, b, *}$
}

\begin{abstract}
Rationale: Astroblastoma is a rare tumor of the central nervous system with uncertain biological behavior and origin. Its histopathological features have been well established, while, to our knowledge, astroblastoma with oligodendroglial-like cells have not been reported.

Patient concerns: A 15-year-old girl presented with nausea, vomiting, headache, and visual disturbance.

Diagnosis: Magnetic resonance imaging revealed a large neoplasm in the left temporal. Histologically, the tumor showed solid and pseudopapillary structure. Immunohistochemical staining showed that the tumor cells were positive for glial fibrillary acidic protein and vimentin. The oligodendroglial-like cells were positive for glial fibrillary acidic protein, vimentin, and oligodendrocyte transcription factor 2. The antigen KI67 labeling index was about 4\%. Sequencing for isocitrate dehydrogenase (IDH) $1 \mathrm{codon} 132$ and IDH2 codon 172 gene mutations showed negative results. Furthermore, fluorescent analysis revealed neither $1 \mathrm{p}$ nor $19 \mathrm{q}$ deletion in the lesion. Based on these findings, the girl was finally diagnosed as astroblastoma.
\end{abstract}

Interventions: A craniotomy with total excision of the tumor was performed.

Outcomes: The follow-up time was 1 year, no evidence of disease recurrence was found in magnetic resonance imaging.

Lessons: Cerebral astroblastoma with oligodendroglial-like cells is a clinically rare tumor of central nervous system. Clear distinction and diagnosis are critical.

Abbreviations: EMA = epithelial membrane antigen, FISH = fluorescent in situ hybridization, GFAP = glial fibrillary acidic protein, $\mathrm{IDH}=$ isocitrate dehydrogenase, NeuN = neuronal nuclear antigen, Olig-2 = oligodendrocyte transcription factor 2, P53 = tumor protein 53, Syn = synaptophysin

Keywords: astroblastoma, case report, oligodendroglial-like cells

\section{Introduction}

Today, according to the 2016 edition of the World Health Organization Classification of Tumors of the Central Nervous System, ${ }^{[1]}$ astroblastoma is belonging to the "other glioma" category. It can occur in persons of any age, but developing in

\footnotetext{
Editor: Maya Saranathan.

Statement of Ethics Subjects have given their written informed consent to publish their case (including publication of images).

The authors have no funding and conflicts of interest to disclose.

The datasets generated during and/or analyzed during the current study are available from the corresponding author on reasonable request.

${ }^{a}$ Department of Pathology, the First Affiliated Hospital of China Medical University, Shenyang, China., ${ }^{b}$ Department of Pathology, College of Basic Medical Sciences, China Medical University, Shenyang, China.

* Correspondence: Juanhan Yu, Department of Pathology, the First Affiliated Hospital and College of Basic Medical Science, China Medical University, 110001, Shenyang, China (e-mail: yujuanhan@foxmail.com).

Copyright (c) 2021 the Author(s). Published by Wolters Kluwer Health, Inc. This is an open access article distributed under the Creative Commons Attribution License 4.0 (CCBY), which permits unrestricted use, distribution, and reproduction in any medium, provided the original work is properly cited. How to cite this article: Gu J, Wang Y, Yu J. Cerebral astroblastoma with oligodendroglial-like cells: a case report. Medicine 2021;100:43(e27570).

Received: 17 July 2021 / Received in final form: 18 September 2021 / Accepted: 7 October 2021

http://dx.doi.org/10.1097/MD.0000000000027570
}

children and young adults. ${ }^{[2,3]}$ Astroblastoma usually develops in cerebral hemispheres, but also in other parts of nervous system. ${ }^{[4]}$ On imaging examination, astroblastomas are well-demarcated masses. ${ }^{[5]}$ Although the microscopic description of astroblastoma in the existing literature is not completely consistent, there are 2 points that can be unified: the perivascular pseudorosette of tumor cells with short and stout cytoplasmic processes, radiating towards central blood vessels that often demonstrate sclerosis; and glial fibrillary acidic protein (GFAP)-positive expression. ${ }^{[6,7]}$ Herein, we report an extremely rare case of astroblastoma accompanied by oligodendroglial-like cells.

\section{Materials and methods}

The resected specimens were fixed with 10\% neutral-buffered formalin and embedded in paraffin blocks. Tissue blocks were cut into $4 \mu \mathrm{m}$ slides, deparaffinized in xylene, rehydrated with graded alcohols, and immunostained with the following antibodies: cytokeratin, GFAP, mutant isocitrate dehydrogenase (IDH)1 R132H, soluble protein-100, vimentin, synaptophysin (Syn), oligodendrocyte transcription factor 2 (Olig-2), alpha-thalasse$\mathrm{mia} / \mathrm{mental}$ retardation syndrome $\mathrm{X}$, neuronal nuclear antigen (NeuN), tumor protein 53 (P53), and antigen KI67 (MaiXin, China). Then, the sections of each specimen were stained with streptavidin-peroxidase (KIT-9720, Ultrasensitive TM S-P, MaiXin, China) following the manufacturer's directions. The 

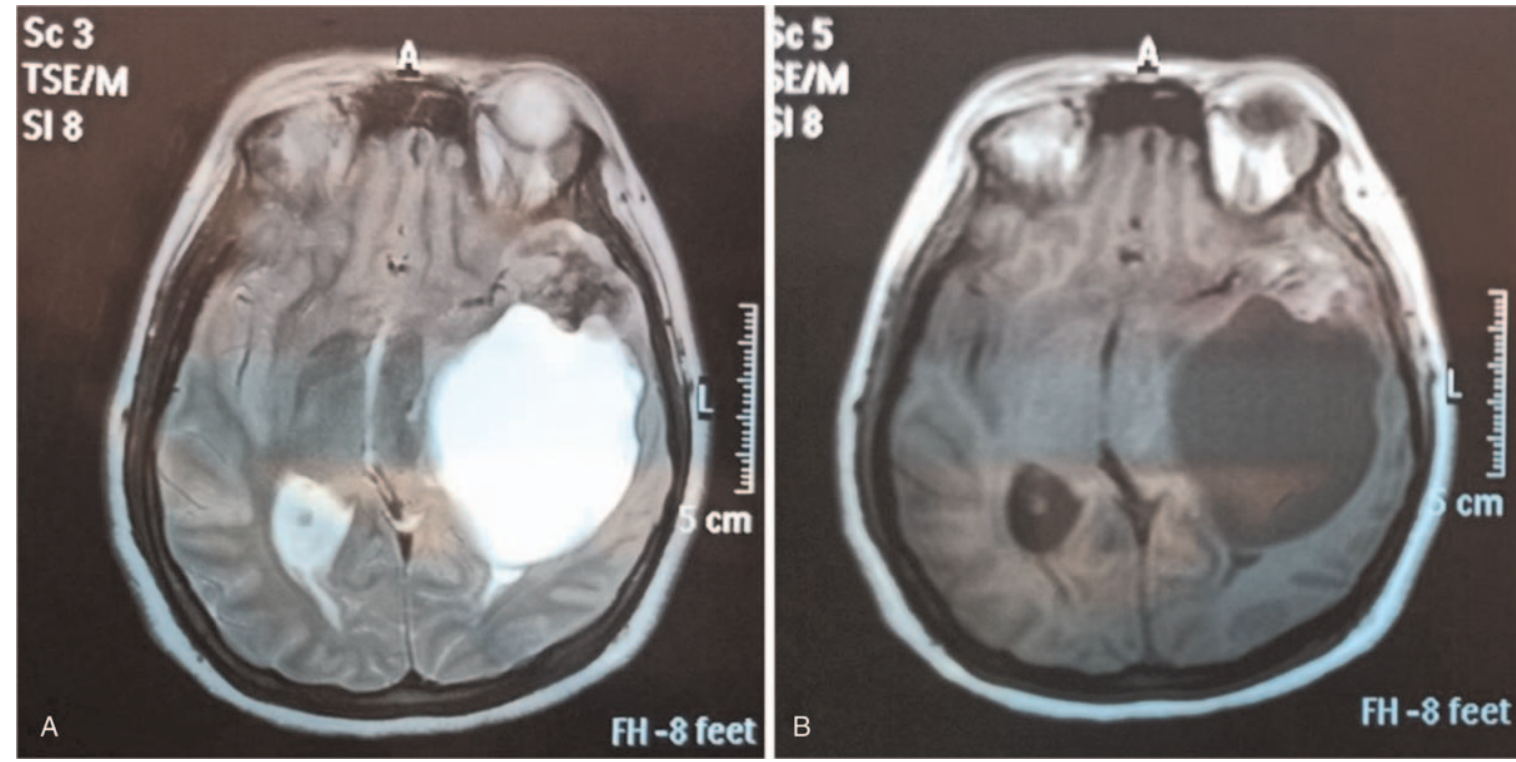

Figure 1. MRI showing a $7.5 \times 5.0 \times 5.0 \mathrm{~cm}$ sized cystic-solid mass in the in the left temporal. Cystic part of the tumor with a uniform long T1 and long T2 signalsss and the edge of is smooth. The solid part of the tumor with not regular edge shows inhomogeneous signal which is slight hypointense on T1-weigted images and slight hyperintense on T2-weighted images. There is no edema signal around the tumor. Tumor occupying effect is obvious, the left ventricle and lateral fissure pool are narrowly compressed and partially invisible. (Tumor occupying effect is obvious, compression of left ventricles and lateral fissure cistern narrowing or disappearance.). The midline structure shift to the right. There was no abnormality in the inner table of the adjacent skull. (A: Axial T1-weighted image. B: Axial T2weighted image.) $\mathrm{MRI}=$ magnetic resonance imaging

chromogen used was diaminobenzidine tetrahydrochloride substrate (DAB kit, MaiXin, China). All samples were slightly counterstained with hematoxylin, dehydrated, and mounted. For the negative controls, each sample was incubated with PBS instead of the primary antibody, as described above.

We performed fluorescent in situ hybridization (FISH) to check for deletions of chromosomes $1 \mathrm{p}$ and 19q. Dual color-probe hybridization was performed with Vysis 1p36/1q25 and 19q13/ 19 p13 FISH Probe Kit (Abbott Molecular, IL) according to the manufacturer's instructions. At least 100 nonoverlapping nuclei were counted; samples were considered to be $1 \mathrm{p}$ - or $19 \mathrm{q}$-deleted when $>30 \%$ of counted nuclei presented 1 target (red) signal and 2 reference (green) signals. Sanger sequencing was used to detect the mutation of IDH 1 and 2 genes.

\section{Case report}

A 15-year-old Chinese female presented with nausea, vomiting, and vertigo for 1 year. Recently, these symptoms gradually aggravate with headache and hypopsia for 1 month. All laboratory test results were normal. Magnetic resonance imaging revealed a large, well-circumscribed, $7.5 \times 5.0 \times 5.0 \mathrm{~cm}$ size cystic-solid lesion in the left temporal. The tumor appeared hyperintense on T1- and T2-weighted images. The signal of most cystic parts of the tumor is uniform, the solid part is uneven. The tumor compression left ventricles and lateral fissure cistern, the midline structure moves to the right (Fig. 1). Radiological diagnosis was "other astrocytic tumor, pilocytic astrocytoma or pleomorphic xanthoastrocytoma”. A craniotomy with total excision of the tumor was performed. The follow-up time was 1 year, no evidence of disease recurrence was found in magnetic resonance imaging.

Small grayish-red fragments of the resected lesion were sent for histological examination. In histological examination, the lesion had 2 patterns in different proportions, astroblastoma area, and oligodendroglial-like cells area, a clear boundary between them (Fig. 2A). In the astroblastoma area, the tumor was composed of poorly cohesive tumor cells forming solid or pseudopapillary structure (Fig. 2B). Importantly, elongated tumor cells having broad footplates were characterized clustered around blood vessels, forming astroblastic pseudorosettes. These cells often seemed polarized, with the nucleus on 1 end and a tail-like cytoplasmic process on the other, possessed abundant eosinophilic cytoplasm and mitosis was rare (Fig. 2C). The tumor tissue was no necrosis or calcification. Blood vessels with no endothelial cell hyperplasia or hyalinization change. Significantly, oligodendroglial-like cells with clear cytoplasm, perinuclear halos, and round nuclei are observed, formed oligodendroglial-like honeycomb appearance, and the mitosis rate is usually low (Fig. 2D).

Immunohistochemical staining showed that the astroblastoma cells were negative for IDH1 R132H (Fig. 3A), cytokeratin, NeuN, Syn, P53, and Olig-2. However tumor cells were revealed positivity for vimentin, soluble protein-100, and alpha-thalassemia/mental retardation syndrome X, GFAP strong positive in the cytoplasm (Fig. 3B). Some tumor cells was positive for epithelial membrane antigen (EMA) in cell membrane (Fig. 3C). The oligodendroglial-like cells were positive for Olig-2, negative for IDH R132H, GFAP, EMA, NeuN, P53, and Syn. The antigen KI67 proliferation index was about $4 \%$. There were no IDH1/2 mutations in the present tumor. FISH analysis revealed in this lesion with no 1 pand $19 \mathrm{q}$ deletion. Based on these findings, the patient was diagnosed with astroblastoma with oligodendrogliallike cells.

\section{Discussion}

Since the original of astroblastoma was reported by Bailey and Cushing, there has been a lot of controversy about its existence 


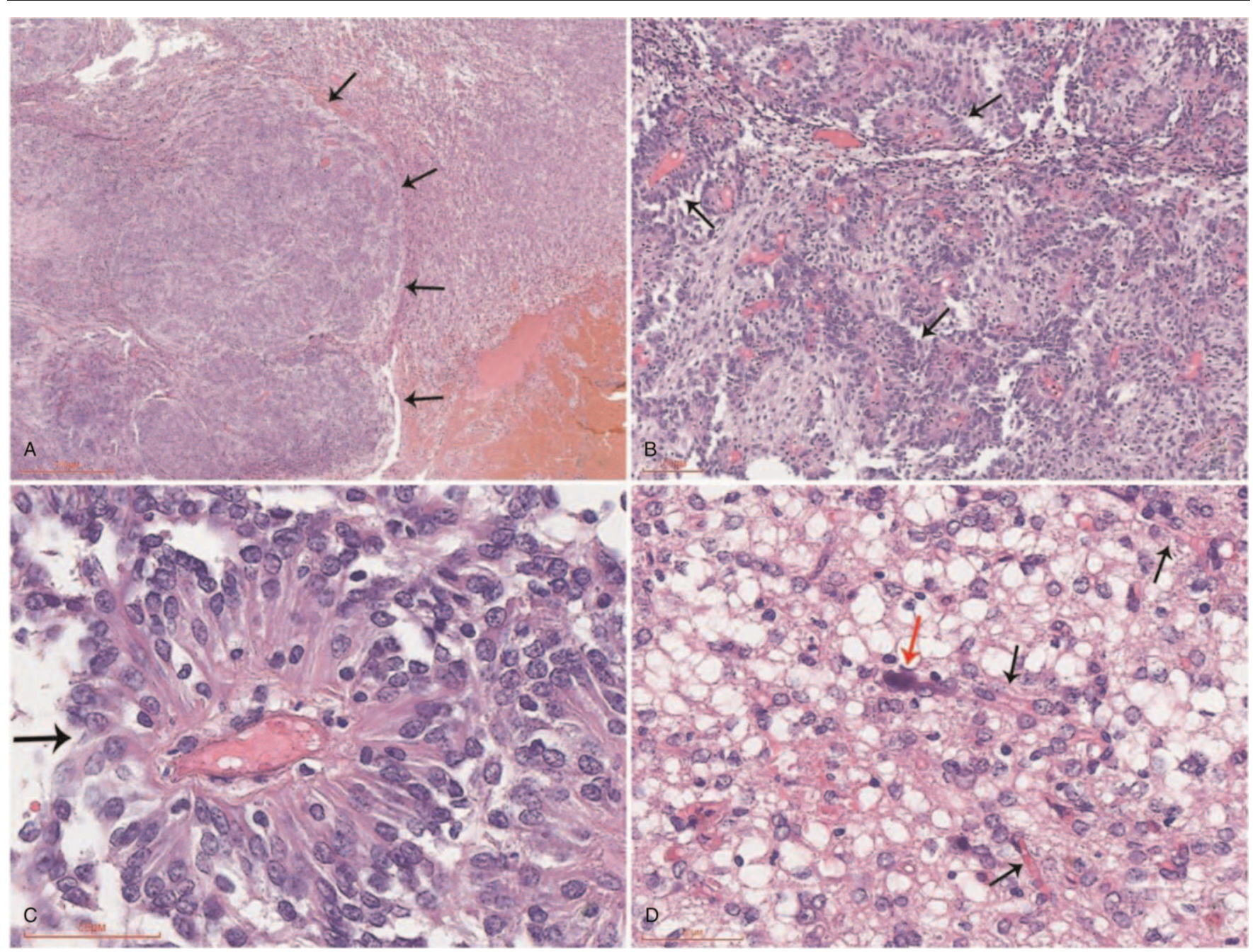

Figure 2. Histopathological findings. (A) Border of astroblastoma with oligodendroglial-like cells area was well defined. (B) The tumor was composed of poorly cohesive tumor cells forming solid or pseudopapillary structure. (C) Astroblastoma area: stout processes extend to the central vessels, forming astroblastic pseudorosettes. (D) Oligodendroglial-like cells area: the tumour cells showed a clear perinuclear halo with delicate "chicken-wire" network of branching capillaries (black arrow) and microcalcification (red arrow).

and origin. ${ }^{[8]}$ Based on microscope observation, astroblastoma was classified as a transitional type between the astrocytoma and the glioblastoma multiform initially. ${ }^{[9]}$ Some scientists believed that GFAP and vimentin positivity in astroblastomas supported the hypothesis that this tumor was derived from the cytogenetically more primitive astroblast, ${ }^{[10,11]}$ or arises from a process of dedifferentiation involving mature astroglial cells. ${ }^{[12]}$ However, an ependymal or tanycyte derivation of astroblastomas understandably is considered by many authors observed the electron microscopic features. ${ }^{[13,14]}$ The tanycyte has been suggested as glial precursor cells and may occur during normal human embryogenesis, which explains the existence of congenital astroblastoma. ${ }^{[15,16]}$ As astroblastoma is often mixed with other types of tumor cells, such as glioblastomas or anaplastic astrocytomas, and the pseudo-chrysanthemum cluster structure also appears in other tumors, there has been controversy about its existence. $^{[17]}$

But as the technology of gene identification matures, more and more specific genes are identified in astroblastoma. The most frequent genes alterations detected were meningioma 1 mutation, gains of chromosome arm 20q, and chromosome 19, losses on $9 \mathrm{q}, 10$, and $\mathrm{X}^{\left[{ }^{[18-20]}\right.}$ These suggested that astroblastomas represent a distinct entity with characteristic cytogenetic features that differ from those of ependymomas and astrocytomas. Because astroblastomas do not have gene detection for large sample cases, there is no unified gene mutation spectrum. It also shows tumors with histologic features of astroblastoma may result from diverse and possibly distinct genetic events. ${ }^{[21]}$

However, many of tumors present with perivascular pseudorosettes and can be confused with each other, such as ependymomas and papillary meningiomas. In our case, astroblastomas exhibiting broad footplates as opposed to the tapering processes seen in ependymoma. In contrast also to ependymomas, the spaces between the pseudorosettes were often rarified. In previous literature, EMA expression especially localized at membrane in astroblastomas, which is same with our case. ${ }^{[22-}$ ${ }^{24]}$ In ependymoma, EMA express along the luminal surface of some ependymal rosettes or manifesting as dot-like perinuclear or ring-like cytoplasmic structures. ${ }^{[25]}$ Therefore, we ruled out the diagnosis of ependymoma by morphology and immunohis- 

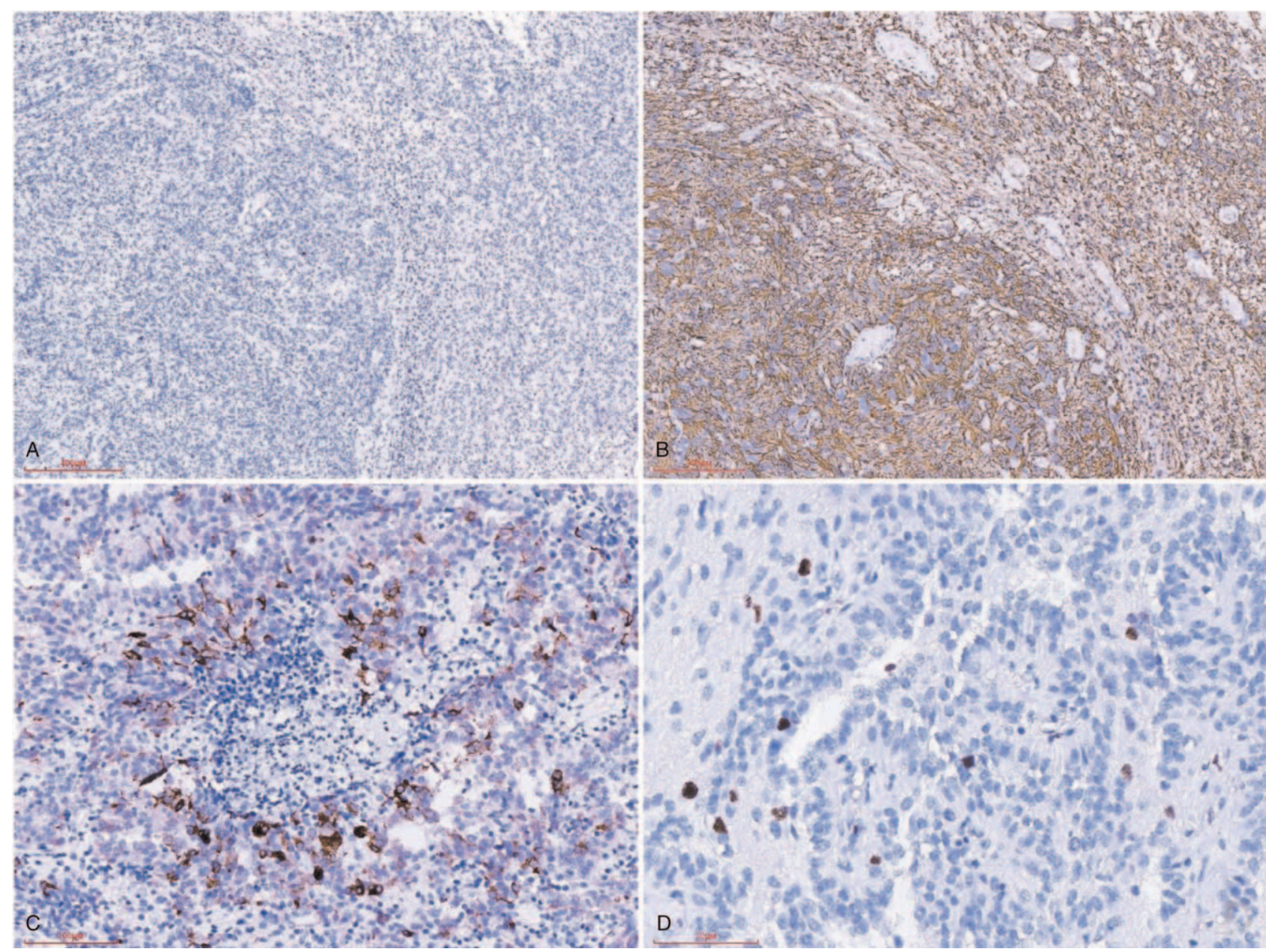

Figure 3. Immunohistochemistry findings. (A) The tumor cells were negative for IDH1 R132H. (B) The tumor cells and the peripheral oligodendroglial-like cells were positive for GFAP. (C) The tumor cells were membranous staining for EMA. (D) The Ki-67 proliferation index was about 4\%. GFAP = glial fibrillary acidic protein, KI-67 $=$ antigen $\mathrm{Kl} 67$.

tochemistry. The distinction between astroblastomas and papillary meningiomas is aided by immunohistochemical features that astroblastomas show positive staining with GFAP. ${ }^{[26]}$ Interestingly, in our case, there are oligodendrocyte-like areas outside the papillary areas, and the boundaries are clear. While, we found neither IDH $1 / 2$ mutation nor 1 p/19q codeletion, so we ruled out the diagnosis of oligodendroglioma. Based on these findings, we diagnosed this tumor as astroblastoma with oligodendroglial-like cells.

Oligodendroglial-like cells can appear in many central nervous system tumors, such as dysembryoplastic neuroepithelial tumor, ${ }^{[27]}$ rosette-forming glioneuronal tumor, ${ }^{[28]}$ papillary glioneuronal tumor, ${ }^{[29]}$ diffuse leptomeningeal glioneuronal tumor, ${ }^{[30]}$ gangliogliomas. ${ }^{[31]}$ Especially, some of these tumors such as gangliogliomas and dysembryoplastic neuroepithelial tumors represent the most frequent epileptogenic tumors in children and young adults. ${ }^{[32]}$ Unlike these, our patients did not have epilepsy. In the previous literature, only Lehman et $\mathrm{al}^{[33]}$ reported that oligodendroglial-like cells appeared in astroblastoma, but it appeared as oligodendrocyte-like cells appeared between astrocytoma cells, which is different from our case.

In the previous literature, different terminology has been used to describe oligodendroglial abnormalities including oligoden- droglial hyperplasia, ${ }^{[34]}$ clusters of oligodendroglia, ${ }^{[35]}$ oligodendroglial hamartoma, ${ }^{[36]}$ and oligodendroglial-like cells. These lesions may represent a spectrum of the same abnormality. These lesions may represent a spectrum of the same abnormality. But the performance of oligodendroglial-like cells under the microscope is not the same, visible oligodendroglial-like cells floated in the mucus-like matrix, or infiltrated in the tumor tissue, or arranged in bundles. Oligodendroglial-like cells and oligodendroglioma have different gene mutation spectrum. Despite oligodendroglial-like morphology, it does not necessarily have chromosome $1 \mathrm{p}$ and $19 \mathrm{q}$ deletion, lacking the characteristic of IDH1 mutation in oligodendroglioma. ${ }^{[37]}$ Therefore, scientists believe that there may be different production mechanisms. In our case, there was no IDH1/2 mutation, or $1 \mathrm{p}$ and $19 \mathrm{q}$ deletion. And there was a clear boundary between the tumor tissue and oligodendroglial-like cells. We believe that the oligodendrogliallike cells here are not oligodendroglioma components, but oligodendroglial-like cells hyperplasia.

Previous case reports showed us that astroblastoma is aggressive tumor with a tendency to recur locally after surgical resection. They have suggested that adjuvant chemotherapy and radiotherapy can improve the survival rate. ${ }^{[38]}$ To our knowledge, astroblastoma with oligodendroglial-like cells is reported 
for the first in the literature, and the prognosis of the patient needs further follow-up.

\section{Conclusions}

In summary, we described a rare case of astroblastoma which accompany with oligodendroglial-like cells areas. Therefore, expanding the scope of pathological examination is necessary for correct diagnosis. In the process of diagnosis, we emphasize that the diagnosis of rare astroblastoma cannot be ignored because of common oligodendroglial-like cells.

\section{Author contributions}

Conceptualization: Juanhan Yu.

Methodology: Yihua Wang.

Writing - original draft: Jian Gu.

Writing - review \& editing: Juanhan Yu.

\section{References}

[1] Louis DN, Perry A, Reifenberger G, et al. The 2016 World Health Organization classification of tumors of the central nervous system: a summary. Acta Neuropathol 2016;131:803-20.

[2] Ahmed KA, Allen PK, Mahajan A, Brown PD, Ghia AJ. Astroblastomas: a surveillance, epidemiology, and end results (SEER)-based patterns of care analysis. World Neurosurg 2014;82:e291-297.

[3] Sughrue ME, Choi J, Rutkowski MJ, et al. Clinical features and postsurgical outcome of patients with astroblastoma. J Clin Neurosci 2011;18:750-4.

[4] Kim DS, Park SY, Lee SP. Astroblastoma: a case report. J Korean Med Sci 2004;19:772-6.

[5] Sener RN. Astroblastoma: diffusion MRI, and proton MR spectroscopy. Comput Med Imaging Graph 2002;26:187-91.

[6] Bonnin JM, Rubinstein LJ. Astroblastomas: a pathological study of 23 tumors, with a postoperative follow-up in 13 patients. Neurosurgery 1989;25:6-13.

[7] Thiessen B, Finlay J, Kulkarni R, Rosenblum MK. Astroblastoma: does histology predict biologic behavior? J Neurooncol 1998;40:59-65.

[8] Bailev P, Bucy PC. Astroblastomas of the brain. Acta Psychiatr Scand 1930;5:439-61.

[9] Cox LB. The cytology of the glioma group; with special reference to the inclusion of cells derived from the invaded tissue. Am J Pathol 1933;9: 839.9-898.9.

[10] Hoag G, Sima AA, Rozdilsky B. Astroblastoma revisited: a report of three cases. Acta Neuropathol 1986;70:10-6.

[11] Navarro R, Reitman AJ, de León GA, Goldman S, Marymont M, Tomita T. Astroblastoma in childhood: pathological and clinical analysis. Childs Nerv Syst 2005;21:211-20.

[12] Walton JN. Pathology of tumours of the nervous system 4th edition, by D. S. Russell and L. J. Rubinstein, vii + 448 pages, 331 illustrations, Edward Arnold, London, 1977, £ 25. 00. J Neurol Sci 1978;36: 163-163.

[13] Rubinstein LJ, Herman MM. The astroblastoma and its possible cytogenic relationship to the tanycyte. An electron microscopic, immunohistochemical, tissue- and organ-culture study. Acta Neuropathol 1989;78:472-83.

[14] Asha U, Mahadevan A, Sathiyabama D, et al. Lack of IDH1 mutation in astroblastomas suggests putative origin from ependymoglial cells? Neuropathology 2015;35:303-11.

[15] Pizer BL, Moss T, Oakhill A, Webb D, Coakham HB. Congenital astroblastoma: an immunohistochemical study. Case report. J Neurosurg 1995;83:550-5.

[16] Soffietti R, Rudà R, Reardon D. Rare glial tumors. Handb Clin Neurol 2016;134:399-415.
[17] Gullotta F, Schindler F, Schmutzler R, Weeks-Seifert A. GFAP in brain tumor diagnosis: possibilities and limitations. Pathol Res Pract 1985; 180:54-60.

[18] Brat DJ, Hirose Y, Cohen KJ, Feuerstein BG, Burger PC. Astroblastoma: clinicopathologic features and chromosomal abnormalities defined by comparative genomic hybridization. Brain Pathol 2000;10:342-52.

[19] Mhatre R, Sugur HS, Nandeesh BN, Chickabasaviah Y, Saini J, Santosh V. MN1 rearrangement in astroblastoma: study of eight cases and review of literature. Brain Tumor Pathol 2019;36:112-20.

[20] Coban EA, Kasikci E, Karatas OF, et al. Characterization of stem-like cells in a new astroblastoma cell line. Exp Cell Res 2017;352:393-402.

[21] Bale TA, Abedalthagafi M, Bi WL, et al. Genomic characterization of recurrent high-grade astroblastoma. Cancer Genet 2016;209:321-30.

[22] Kubota T, Sato K, Arishima H, Takeuchi H, Kitai R, Nakagawa T. Astroblastoma: immunohistochemical and ultrastructural study of distinctive epithelial and probable tanycytic differentiation. Neuropathology 2006;26:72-81.

[23] Yuzawa S, Nishihara H, Tanino $M$, et al. A case of cerebral astroblastoma with rhabdoid features: a cytological, histological, and immunohistochemical study. Brain Tumor Pathol 2016;33:63-70.

[24] Yapıcıer Ö, Demir MK, Özdamarlar U, Kılıç D, Akakın A, Kılıç T. Posterior fossa astroblastoma in a child: a case report and a review of the literature. Childs Nerv Syst 2019;35:1251-5.

[25] Kawano N, Yasui Y, Utsuki S, Oka H, Fujii K, Yamashina S. Light microscopic demonstration of the microlumen of ependymoma: a study of the usefulness of antigen retrieval for epithelial membrane antigen (EMA) immunostaining. Brain Tumor Pathol 2004;21:17-21.

[26] Shuangshoti S, Mitphraphan W, Kanvisetsri S, et al. Astroblastoma: report of a case with microsatellite analysis. Neuropathology 2000; 20:228-32.

[27] Bilginer B, Söylemezoğlu F, Cila A, Akalan N. Intraventricular dysembryoplastic neuroepithelial tumor-like neoplasm with disseminated spinal tumor. Turk Neurosurg 2009;19:69-72.

[28] Vajtai I, Arnold M, Kappeler A, et al. Rosette-forming glioneuronal tumor of the fourth ventricle: report of two cases with a differential diagnostic overview. Pathol Res Pract 2007;203:613-9.

[29] Ishizawa T, Komori T, Shibahara J, et al. Papillary glioneuronal tumor with minigemistocytic components and increased proliferative activity. Hum Pathol 2006;37:627-30.

[30] Chen W, Kong Z, Fu J, et al. Diffuse leptomeningeal glioneuronal tumour (DLGNT) with hydrocephalus as an initial symptom: a case-based update. Childs Nerv Syst 2020;36:459-68.

[31] Appay R, Fina F, Macagno N, et al. Duplications of KIAA1549 and BRAF screening by Droplet Digital PCR from formalin-fixed paraffinembedded DNA is an accurate alternative for KIAA1549-BRAF fusion detection in pilocytic astrocytomas. Mod Pathol 2018;31:1490-501.

[32] Nagaishi M, Arai M, Osawa T, et al. An immunohistochemical finding in glioneuronal lesions associated with epilepsy: the appearance of nestinpositive, CD34-positive and tau-accumulating cells. Neuropathology 2011;31:468-75.

[33] Lehman NL, Hattab EM, Mobley BC, et al. Morphological and molecular features of astroblastoma, including BRAFV600E mutations, suggest an ontological relationship to other cortical-based gliomas of children and young adults. Neuro Oncol 2017;19:31-42.

[34] Schurr J, Coras R, Rössler K, et al. Mild malformation of cortical development with oligodendroglial hyperplasia in frontal lobe epilepsy: a new clinico-pathological entity. Brain Pathol 2017;27:26-35.

[35] Inage Y, Halliday WC, Go C, et al. Histopathology of cortex and white matter in pediatric epileptic spasms: comparison with those of partial seizures. Brain Dev 2012;34:118-23.

[36] Marucci G, Giulioni M, Martinoni M, Volpi L, Michelucci R. Oligodendroglial hamartoma: a potential source of misdiagnosis for oligodendroglioma. J Neurooncol 2011;101:325-8.

[37] Gupta S, Rangari KV, Mehrotra A, Pal L, Jaisawal AK, Kumar R. Temporal lobe angiocentric glioma with oligodendroglioma-like areas: a rare association of an uncommon tumor. A case report with review of literature. Childs Nerv Syst 2020;36:641-6.

[38] Sarper B, Yaprak Bayrak B, Halis H, Alparslan B, Yeni Bayraktar H. Malignant astroblastoma. Balkan Med J 2020;37:224-5. 